\title{
534 Stress and Strain Analysis in Temper Rolling for Mild Steel Sheet by Elastic-Plastic Finite Element Method
}

\author{
Ikuo YARITA* \& Yasuhito SATOH** \\ * Department of Mechanical Engineerring, Chiba Institute of Technology \\ 2-17-1 Tsudanuma, Narashino, Chiba 275-0016, Japan, yarita@pf.it-chiba.ac.jp \\ ** Graduate student, Chiba Institute of Technology
}

\begin{abstract}
The temper rolling is applied to eliminate the stretcher strain, to improve the flatness and to control the surface roughness of material rolled. However, there are some problems remains in analysis of the temper rolling process. The classical rolling theories based on the rigid plastic theory, can not deal with un-uniform elastic-plastic deformation in the temper rolling process due to the deformation is particularly concentrated near the surface layer.

This paper presents elastic-plastic finite element analyses of stress and deformation behaviors in the plane strain temper rolling for as-annealed mild steel sheet. In the analyses, the upper yield point, the lower yield point and yield point elongation are taken into account for the stress-strain relation of the material deformed. For the contact boundary between the roll and the deforming material, both slipping and sticking are considered, and the Coulomb friction law is employed to represent the slipping friction.

The calculations are conducted about thickness reduction of $0.5 \%, 1.0 \%, 2.0 \%$ and $5.0 \%$, and the coefficient of friction in the slipping zone of $0.1,0.2$ and 0.3 to investigate the effect on stress and strain behaviors. In the case of reduction of $0.5 \%$, the yield stress moves down from the upper yield point to the lower yield point, and in the reduction of $2.0 \%$, the yield point elongation is completely finished.

Key words: Temper rolling, Mild steel sheet, Stress-strain behavior, Plane strain, Elastic-plastic finite element analysis
\end{abstract}

\section{Introduction}

The temper rolling is applied to eliminate the stretcher strain occurred in subsequent sheet forming process and to improve the flatness and the surface roughness of strip being rolled. However, there are some unsolved problems remained such as temper rolling theory, mechanism on formation of surface roughness of material rolled and mechanism of poor flatness as cross buckling. The classical rolling theories based on the rigid plastic theory, can not deal with nonuniform elastic-plastic deformation in the thickness direction in the temper rolling process due to the shear deformation is particularly concentrated on near the surface layer of the deforming material.
In this study, elastic-plastic finite element analyses of stress and deformation behaviors in the plane strain temper rolling for as-annealed mild steel sheet with isotropic structure are attempted. In the analyses, the upper yield point, the lower yield point and yield point elongation are taken into account for the stress-strain relation of the material being deformed. For the contact boundary between the roll and the material rolled, both slipping and sticking are considered, and the Coulomb friction law is employed to represent the slipping friction.

\section{Outline of finite element formulation}

The updated Lagrange code is employed to the elastic-plastic finite element computer 
$\operatorname{program}^{1,2^{\prime}}$.

\subsection{Elastic-plastic finite deformation theory}

The Jaumann rate of Kirchoff stress is employed to the incremental structure of isotropic elastic-plastic constitutive relation. The Prandtl-Reuss constitutive equation can be written by

$$
\begin{aligned}
& \tau_{\mathrm{ij}}^{*}=2 \mathrm{G}\left[\delta_{\mathrm{ik}} \delta_{\mathrm{jl}}+\frac{v}{1-2 v} \delta_{\mathrm{ij}} \delta_{\mathrm{kl}}\right. \\
& \left.-\frac{\theta}{1+(\mathrm{h} / 3 \mathrm{G})} \frac{3 \tau_{\mathrm{ij}}^{\prime} \tau_{\mathrm{kl}}^{\prime}}{2 \mathrm{Y}^{2}}\right] \mathrm{D}_{\mathrm{kl}}=\mathrm{C}_{\mathrm{ijkl}} \mathrm{D}_{\mathrm{kl}}
\end{aligned}
$$

where,

$$
D_{i j}=\frac{1}{2}\left(v_{i, j}+v_{j, i}\right)
$$

$\tau_{i j}$ is the co-rotational rate of the Kirchhoff stress, $\sigma_{i j}$ is the Cauchy stress, $D_{i j}$ is the rate of deformation tensor, $v_{i}$ is the velocity component, $v_{i, j}$ is the velocity gradient, $G$ is the shear modulus, $v$ is the Poisson ratio, $h$ is the current plastic tangential modulus, $\tau_{\text {ij }}$ is the Kirchhoff stress, $\tau_{\mathrm{ij}}^{\prime}$ is the deviatoric Kirchhoff stress, $\mathrm{Y}$ is the current Kirchhoff yield stress, $\theta$ is set to zero for elastic loading or unloading and to unity for plastic loading and $\delta_{\mathrm{ij}}$ is the Kronecker delta.

The structure of this theory was discussed by E.H.Lee ${ }^{3)}$ and the formulation was applied to the finite element large deformation analysis by McMeeking and Rice ${ }^{4}$.

The virtual work equation based on Hill's variational principle ${ }^{5)}$ can be written in the updated Lagrange form:

$$
\begin{aligned}
& \int \frac{\rho}{\rho^{0}}\left[\tau_{i j}^{*} \delta D_{i j}-\tau_{i j} \delta\left(D_{i k} D_{l j}-\frac{v_{k, i} v_{k, j}}{2}\right)\right] d V \\
& =\int_{\delta} f_{i} \delta v_{i} d S+\int b_{i} \delta v_{i} d V
\end{aligned}
$$

where, $f_{i}$ is the traction rate, $b_{i}$ is the body force rate.

\subsection{Finite element stiffness equation}

The velocity component $v_{i}$ and the deformation rate component $D_{i j}$ can be expressed by the rate of nodal displacements $\{\phi\}$.

$$
\mathrm{v}_{\mathrm{i}}=\left[\mathrm{N}_{\mathrm{i}}\right]\{\dot{\phi}\}, \quad \mathrm{D}_{\mathrm{ij}}=\left[\mathrm{B}_{\mathrm{ij}}\right]\{\dot{\phi}\}
$$

where, $\left[\mathrm{N}_{\mathrm{i}}\right]$ is the shape function and $\left[\mathrm{B}_{\mathrm{ij}}\right]$ is the strain-displacement matrix.

Thus, $v_{i, j}$ can be written as

$$
\mathrm{v}_{\mathrm{i}, \mathrm{j}}=\left[\mathrm{N}_{\mathrm{i}}\right]_{j}\{\phi\}
$$

The variational equation (3) reduces to the finite element stiffness equation

$$
\frac{\rho}{\rho^{0}}\left[\int[B]^{T}[C \mid B] d V+[K s]\right]\{\dot{\phi}\}=\{\dot{P}\}
$$

where,

$$
[K s]=-\int\left(2\left[B_{k i}\right]^{\mathrm{T}} \tau_{i j}\left[B_{k j}\right]-\left[N_{k}\right]_{, i}^{T} \tau_{i j}\left[N_{k}\right]_{, j}\right) d V
$$

is called the initial stress stiffness, and

$$
\{\dot{P}\}=\int[N]^{T}\{\dot{b}\} d V+\int[N]^{T}\{\dot{f}\} d S
$$

is called the force rate vector.

\section{Plane strain temper rolling analysis}

In this study, slipping and sticking are taken into account for the frictional boundary conditions between the roll and the deforming material as shown in Fig.1. The Coulomb friction law is used to represent the slipping friction. In any case where the Coulomb friction law must be accounted for, the frictional traction is not being explicitly prescribed and the symmetry of the composite stiffness matrix is destroyed. To solve non-symmetric stiffness equation, the Predictor-Corrector method is employed.

In additions, several difficulties are encountered for boundary conditions as follows:

(1) The positions of the entry point D and the exit point $\mathrm{G}$ through the contact between the roll and the deforming material are not determined by geometry.

(2) Through the contact, frictional conditions change from slipping to sticking and to slipping with direction changes of frictional force. And, their locations $\mathrm{E}$ and $\mathrm{F}$ are not determined by geometry. 


\subsection{Boundary conditions}

The process of the temper rolling, as shown in Fig.1, is analyzed under the plane-strain condition $^{6,7}$. Since the process is symmetric with respect to the $\mathrm{x}$-axis, the analysis is performed for half of the work-piece. The boundary conditions are as follows:

i) along $\mathrm{AB}$ ( $\mathrm{x}$-axis)

$$
\mathrm{v}_{\mathrm{y}}=0
$$

ii) along CD and GF (free surface)

$$
\mathrm{f}_{\mathrm{t}}=\mathrm{f}_{\mathrm{n}}=0
$$

iii) along DE (slipping in inlet)

$$
v_{n}=0, \quad f_{t}=-\mu f_{n} \quad\left(\dot{f}_{t}=-\mu f_{n}\right)
$$

iv) along $\mathrm{EF}$ (sticking)

$$
\mathrm{v}_{\mathrm{n}}=0, \quad \mathrm{v}_{\mathrm{n}}=\omega \mathrm{R}
$$

v) along FG (slipping in outlet)

$$
v_{n}=0, \quad f_{t}=\mu f_{n} \quad\left(f_{t}=\mu f_{n}\right)
$$

where, $v_{y}$ is the velocity component in the $y$ direction, $v_{n}$ and $v_{t}$ are the normal and tangential velocity components respectively, $f_{n}$ and $f_{t}$ are the normal and tangential components of nodal force respectively, $\omega$ is the angular velocity of the roll, $\mathrm{R}$ is the roll radius and $\mu$ is the coefficient of slipping friction between the roll and the deforming material.

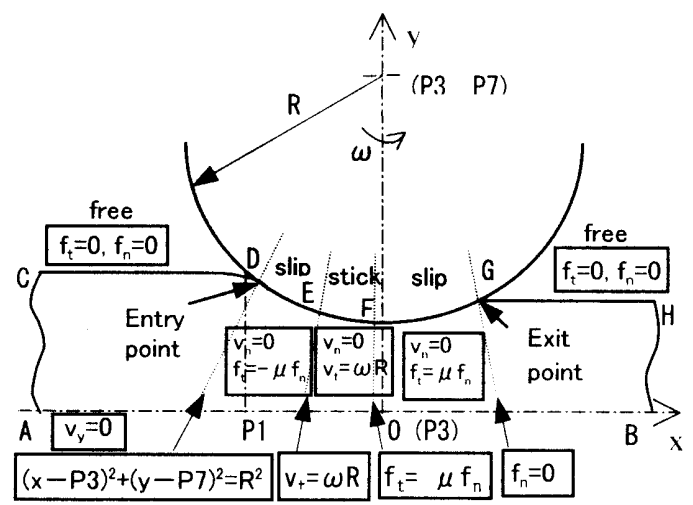

Fig.1 Boundary conditions in temper rolling

\subsection{Boundary criteria}

In rolling process, the material points move into roll contact zone from free surface, and the boundary conditions change from slipping, to sticking and to slipping, finally the points move out free surface. In order to complete this process, the points $\mathrm{D}, \mathrm{E}, \mathrm{F}$ and $\mathrm{G}$ are determined as follows:

(1) Point D ; $(\mathrm{x}-\mathrm{P} 3)^{2}+(\mathrm{y}-\mathrm{P} 7)^{2}=\mathrm{R}^{2}$

(2) Point $\mathrm{E} ; \mathrm{v}_{\mathrm{t}}=\omega \mathrm{R}$

(3) Point $F ; f_{t}=\mu f_{n}<0$

(4) Point $G ; f_{n}=0$

where, P3 is the $\mathrm{x}$-coordinate of the lowest point of roll, ie. $x=0, P 7$ is the $y$-coordinate of roll center.

\section{Numerical analysis}

\subsection{Calculating conditions}

The stress and strain fields for the plane-strain temper rolling procedure are analyzed for half of a sheet. The typical computing conditions for the material data and the rolling conditions are shown in Table 1 . The material rolled to $0.5, \quad 1.0,2.0$ and $5.0 \%$ reductions of the entering sheet with $1.20 \mathrm{~mm}$ in thickness. The roll is assumed to be a rigid body.

\begin{tabular}{|c|c|c|c|}
\hline \multirow{2}{*}{ 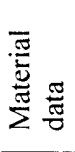 } & $\begin{array}{l}\text { Physical } \\
\text { parameter }\end{array}$ & $\begin{array}{l}\text { Bulk modulus } \\
\text { Shear modulus } \\
\text { Poisson ratio }\end{array}$ & $\begin{array}{l}164 \mathrm{GPa} \\
79 \mathrm{Gpa} \\
0.29\end{array}$ \\
\hline & Geometry & Initial thickness & $1.20 \mathrm{~mm}$ \\
\hline \multirow{2}{*}{ 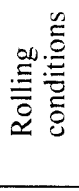 } & $\begin{array}{l}\text { Physical } \\
\text { parameter }\end{array}$ & $\begin{array}{l}\text { Coefficient } \\
\text { of friction }\end{array}$ & $0.1,0.2,0.3$ \\
\hline & Geometry & $\begin{array}{l}\text { Roll radius } \\
\text { Reduction ratio }\end{array}$ & $\begin{array}{l}762 \mathrm{~mm} \\
0.005,0.01,0.02 \\
0.05\end{array}$ \\
\hline \multirow{2}{*}{ 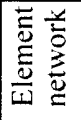 } & Network & \multicolumn{2}{|l|}{$4 \times 60$} \\
\hline & Element & \multicolumn{2}{|c|}{$\begin{array}{l}\text { Four noded constant } \\
\text { dilatation quadrilateral }\end{array}$} \\
\hline
\end{tabular}
The coefficients of friction in slipping zone are attempted as $\mu=0.1,0.2$ and 0.3 in the each reduction.

Table 1 Typical computing conditions

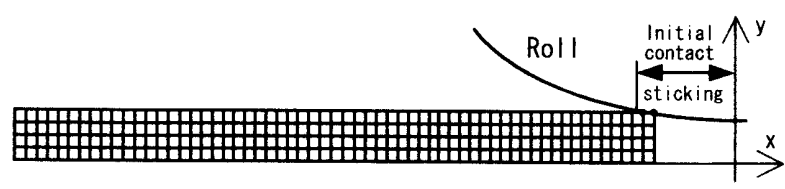

Fig.2 Initial undeformed finite element configuration

An initial undeformed finite element configuration for this plane-strain temper rolling 
analysis is shown in Fig.2.

The finite element network employed for this analysis is chosen $4 \times 60$ array of four nodded constant dilatation quadrilaterals. The computation begins under 2 element nodes at leading end of the material contact with rolls in sticking conditions.

Fig.3 shows the equivalent stressequivalent plastic strain curve for the materials of mild steel to determine the plastic tangential modulus $h$ and the yield stress $Y$ in eqn.(1). The equivalent stress - plastic strain curve takes account of the upper yield point, the lower yield point and the yield point elongation characterized in mild steel.

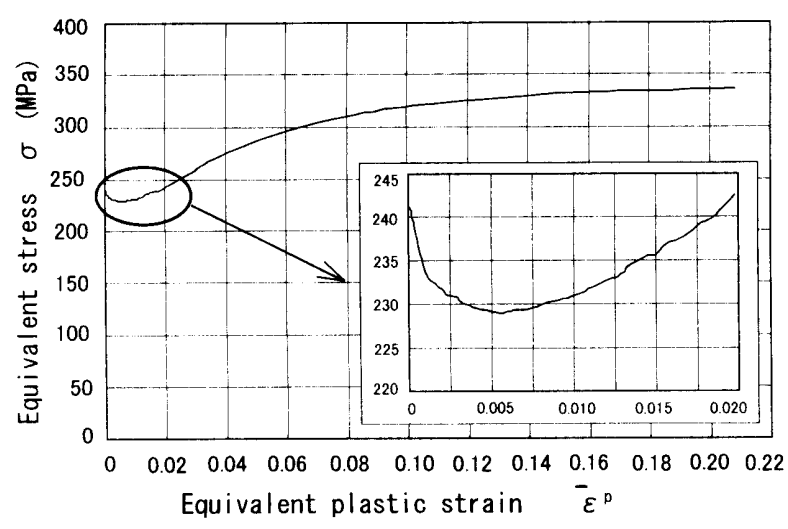

Fig.3 Equivalent stress - equivalent plastic strain curve of mild steel sheet

\subsection{Calculated results}

The rolling calculation was continued until the first 11 nodes on the boundary surface moved out the roll bite and became free. Fig. 4 shows an

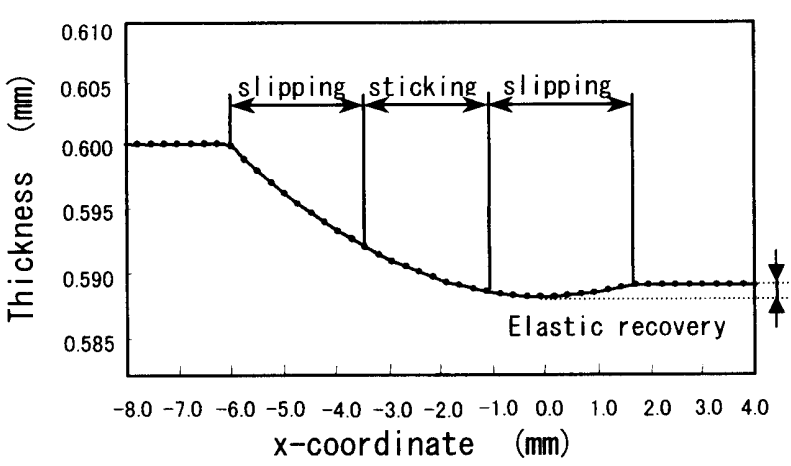

Fig.4 Example of calculated thickness distribution $(r=2.0 \%, \mu=0.2)$ example of calculated thickness distribution in the roll bite in the case of $2.0 \%$ in reduction with coefficient of friction of $\mu=0.2$ in slipping zones.

It can be seen that the frictional boundary condition changes from slipping to sticking and to slipping, and elastic recovery in thickness occurs at outlet of roll bite.

Fig.5 shows the comparison of the equivalent plastic strain $\bar{\varepsilon}$ p distributions with the coefficients of friction at thickness reduction of 0.5 and $2.0 \%$. The equivalent plastic strains in $0.5 \%$ reduction, in the case that flow stress of the deforming material is work-softening, indicate small difference between both frictions and become almost uniform distributions due to small strain. However, the internal elements have slightly larger strains comparing with those in surface elements. In the case of the small friction in more than $1.0 \%$ reduction, the equivalent plastic strain distributions become uniform in the thickness direction at each reduction. The other hand, the equivalent plastic strain distributions in the larger friction of $\mu=0.3$ show that nonuniform strain distributions in the thickness direction such that surface elements have bigger strains than internal elements. The sticking zone enlarges with the coefficient of friction $\mu$.

Fig.6, 7 and 8 show distributions of average longitudinal stress $\sigma_{\mathbf{x x}}$, average vertical stress $\sigma \quad y \mathrm{y}$ and average shear stress $\sigma \quad \mathrm{xy}$ respectively for each friction under the conditions of thickness reduction of $0.5 \%$ and $2.0 \%$. It is seen that stress distributions are same behaviors in both $0.5 \%$ and $2.0 \%$ reductions with respect to every friction.

The larger coefficient of friction, the less uniform stress distribution $\sigma \mathrm{xx}$ in the thickness direction. In the case of small friction, the stress of $\sigma \mathrm{xx}$ indicates the uniform distribution. Surface elements in the outlet have tensile residual stresses and center elements have compressive residual stresses in small friction. The other hand, in larger friction, surface elements have compressive residual stresses and center elements have tensile residual stresses. 

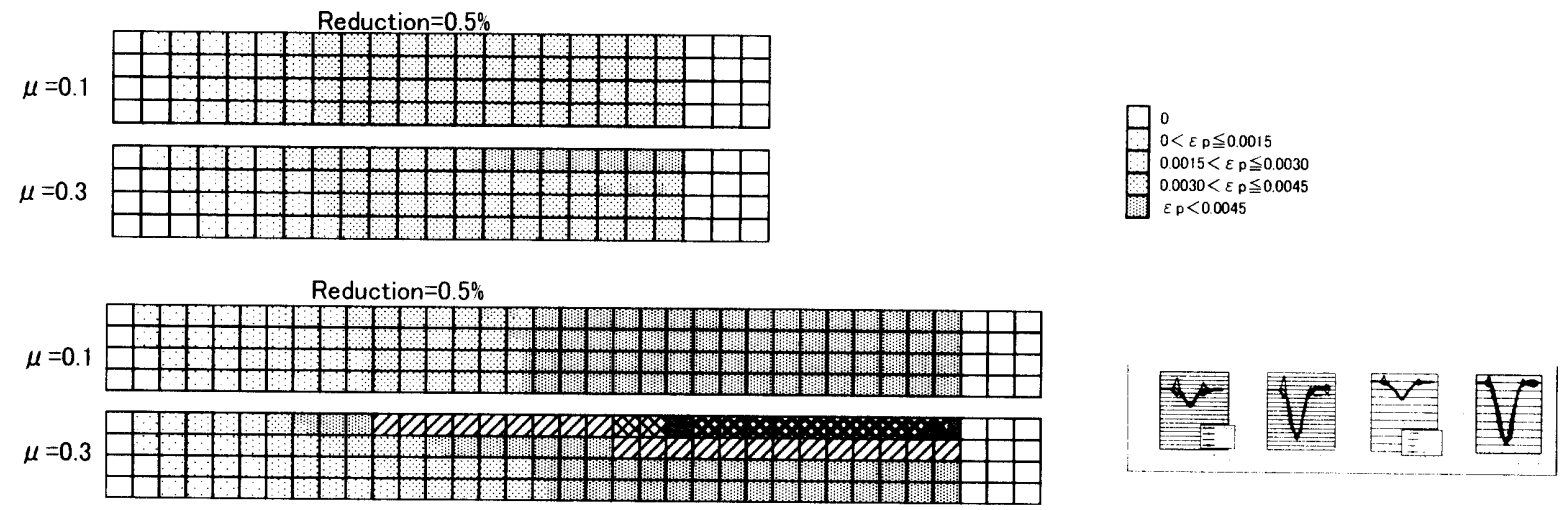

Fig.5 Equivalent plastic strain \& p distributions comparing with reduction $0.5 \%$ and $2.0 \%$

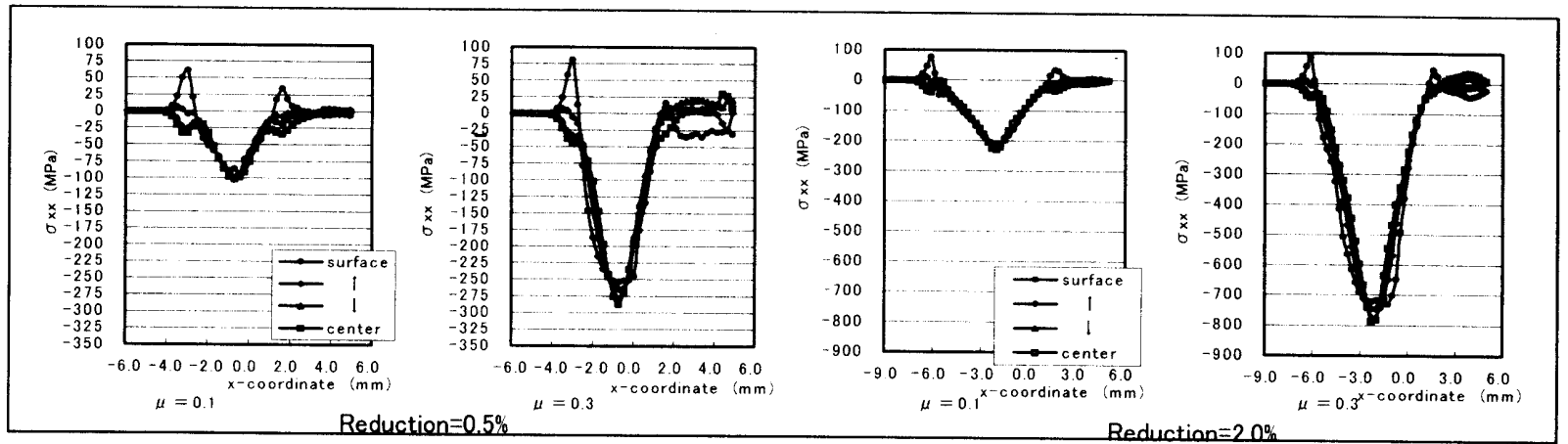

Fig.6 Longitudinal stress $\sigma{ }_{\mathrm{xx}}$ distributions comparing with reduction $0.5 \%$ and $2.0 \%$

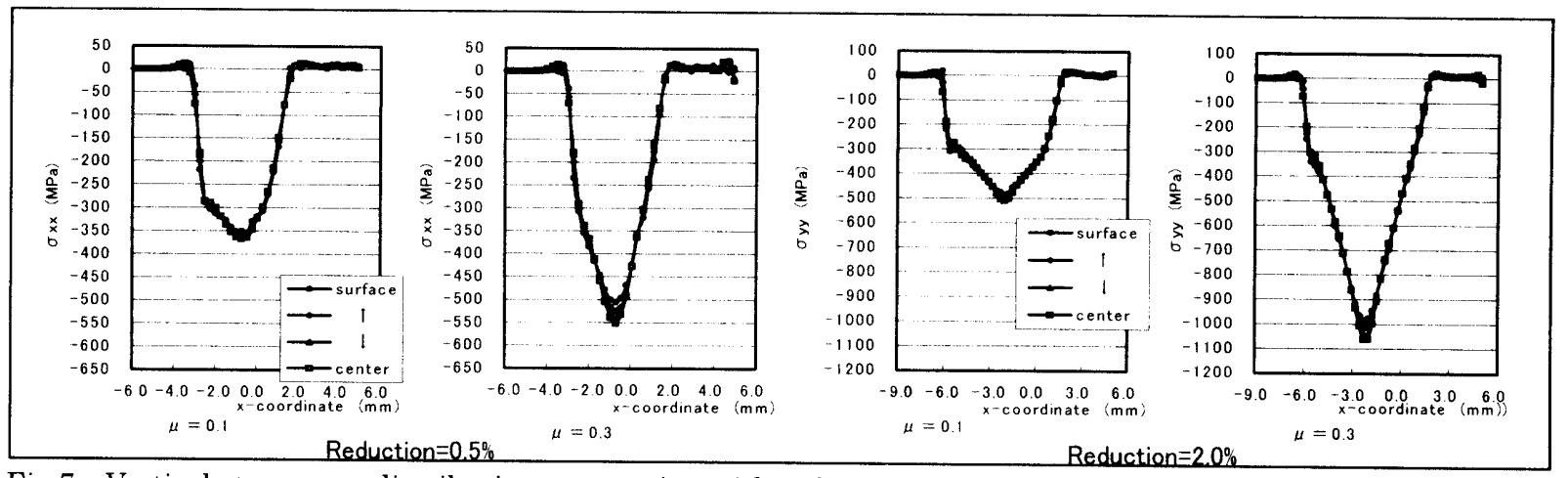

Fig.7 Vertical stress $\sigma_{\text {yy }}$ distributions comparing with reduction $0.5 \%$ and $2.0 \%$

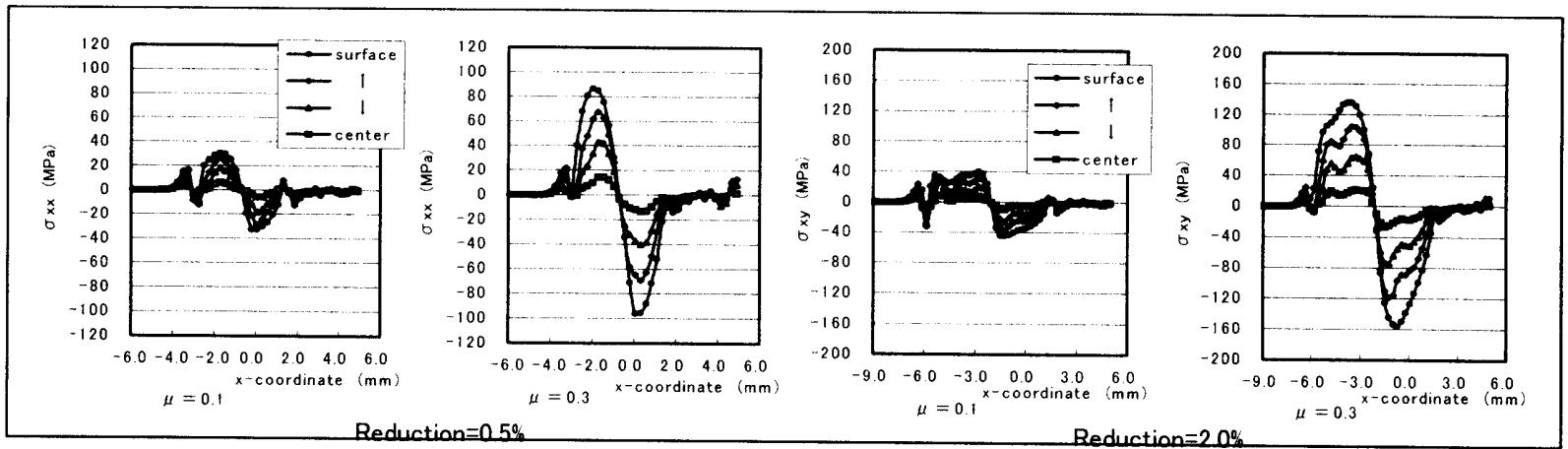

Fig.8 Shear stress $\sigma_{y y}$ distributions comparing with reduction $0.5 \%$ and $2.0 \%$ 
The vertical stress distributions $\sigma y y$ are almost same values in the thickness direction along the roll contact at every friction. The elastic stress can be appeared at inlet, and the friction hill is clearly observed in the contact zone with the increase of the coefficient of friction.

The shear stress $\sigma_{x y}$ distributions are less uniform in the thickness direction, but in the case of small friction, the absolute value of the shear stress is negligible compared with that in the larger frictions.

Considering with both calculated results of the equivalent strain $\varepsilon^{p}$ distribution and the stress distributions of $\sigma_{\mathbf{x x}}, \sigma_{\mathbf{y y}}$ and $\sigma \mathbf{x y}$, the classical rolling theory such as the equation by Bland\&Ford may be applicable to the temper rolling analysis in the small friction as the lubricated rolling.

\section{Conclusions}

The elastic-plastic finite element analysis of the temper rolling for mild steel has been performed. The upper and lower yield points and the yield point elongation were taken into account for the stress-strain relation of mild steel being rolled. Both slipping and sticking were considered for the frictional boundary between the rolls and the material rolled. The results obtained are as follows:

(1) The reduction of $0.5 \%$ in which flow stress of the deforming material is work-softening indicates the nearly uniform equivalent plastic strain distributions, though the internal elements have slightly larger strains.

(2) In the case of larger friction, sticking zone is enlarged in the contact frictional boundary between the rolls and the material rolled. That causes severe shear deformation in the surface layer of the material. The equivalent plastic strain $\epsilon^{p}$ and the stresses $\sigma_{\mathrm{xx}}$ and $\sigma_{\mathrm{xz}}$ indicate nonuniform distributions in the thickness direction.

(3) The small friction provides the uniform equivalent plastic strain and the uniform stress distributions in the thickness direction. That supposes the classical rolling theory may be applicable to the lubricated temper rolling analysis.

\section{References}

1)E.H.Lee, R.L.Mallett \& W.H.Yang: Computer Meth. in Appl. Mech. Engng. Vol.10 (1977) p339-353

2)E.H.Lee, R.L.Mallett \& R.M.McMeeking: Numerical Modeling of Manufacturing Processes. (1977), p 19

3)E.H.Lee: Theory of Metal Forming Process. (Ed. H.Lippmann, Springer-Verlag), (1977), p81

4)R.M.McMeeking \& J.R.Rice: Int. J. Solids Structures.

Vol.11 (1975), p601

5)R.Hill: J. Mech. Phys. Solids. Vol.7 (1959), p209

6)I.Yarita, R.L.Mallett \& E.H.Lee: steel research. Vol.56, No.5 (1985), p225

7)I.Yarita \& Y.Satoh: Advanced Tech. Plasticity. Vol.2 (1990), p613 